\title{
Patterns and Trends in the Use of Herbal Products, Herbal Medicine and Herbal Medicinal Products
}

\section{Abstract}

Used as authorized medicines or dietary supplements herbal products gain a rising and high interest by patients as well as by health care professionals. In industrialized countries, 10-50\% of the population regularly uses herbal products. According to surveys, the main reason to use herbal products in these countries is the assumption of a better tolerability compared to synthetic drugs. Whereas in developing countries herbal medicines are mostly the only available and affordable treatment option. Surveys from industrialized countries reveal as main health areas in which herbal products are used upper airway diseases including cough and common cold; other leading causes are gastrointestinal, nervous and urinary complaints up to painful conditions such as rheumatic diseases, joint pain and stiffness. Risks associated with the use of a (herbal) medicinal product are assessed by health authorities during the approval procedure and is monitored during marketing by systematic continuous pharmacovigilance activities. This process favors authorized or registered herbal medicinal products.

Keywords: Herbal medicinal product; Indication; Patterns of use; Global perspective; Complementary and alternative medicine; Phytotherapy

Review Article
Volume 9 Issue 6 - 2017
Tankred Wegener*
Registration C and NC Expert Reports - Studies, Germany
*Corresponding author: Tankred Wegener, Registration - C
and NC Expert Reports- Studies, Brueckstrasse 11, 69469
Weinheim, Germany, Email: t.wegener@consulting-hmp.de
Received: November 22, 2016 | Published: December 07,
2017

Abbreviations: RCT: Randomized Clinical Trials; HMP: Herbal Medicinal Products; WHO: World Health Organization; HM: Herbal Medicines; CAM: Complementary and Alternative Medicine

\section{Introduction}

The interest in the practical use of herbal substances and preparations for medicinal purposes is growing continuously worldwide. This is reflected by numerous publications describing the interest of consumers and patients, e.g. from epidemiological studies, by an increasing number of scientific publications including those on randomized clinical trials (RCT) [1] in the worldwide literature as well as by publications which deal with specific aspects of the therapeutic use of herbals or herbal medicinal products, e.g. reviews, meta-analyses or safety aspects (Figure 1).

The present article highlights some aspects of the use of herbal or botanical substances and preparations for medicinal purposes globally and specifically compares two different markets as examples: the German market with predominantly authorized herbal medicinal products (HMP) and the market in the United States with almost exclusively herbal or botanical dietary supplements.

\section{Definition and Regulation}

The World Health Organization (WHO) defines herbal medicines (HM) as remedies containing crude "herbs, herbal materials, herbal preparations and finished herbal products that contain as active ingredients parts of plants, or other plant materials, or combinations" [2]. This definition covers three different categories: a) authorized herbal medicinal products according to the European Union framework for medicines regulation [EC 2001/83], b) botanical or dietary herbal supplements used for medicinal purposes like in the United States and almost all other countries, and c) single, individual preparations that are prepared and/or used by the consumers themselves or prescribed by a herbal practitioner, a physician or a pharmacist.

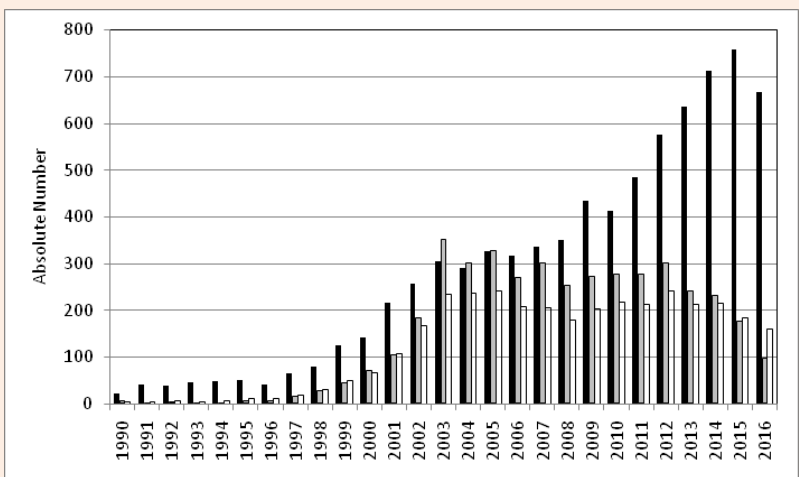

Figure 1: Interest in herbal medicine as shown by the absolute numbers of publications on herbal drugs in PubMed, obtained with search terms for all publications on 'herbal medicine' OR 'phytotherapy' (white bars; reduced to $1 / 10$ of size), all publications on 'herbal medicine' OR 'phytotherapy' AND clinical/controlled clinical trials (gray bars), and all publications on 'herbal medicine' OR 'phytotherapy' AND safety aspects ('adverse reactions or events'; black bars); searches were conducted by using relevant medical subject headings (MeSH) for the calendar years 1990 to 2016.

In industrialized countries with sufficient medicinal care, the use of herbal products and preparations for medicinal purposes and/or of herbal medicinal products (HMP) is considered as part 
of Complementary and alternative medicine (CAM) [3-5]. Herbal (botanical) products (HP) of these different categories, including dietary supplements as authorized HMP, are used as an alternative medicine to synthetic pharmaceuticals or as a complementary medicine together with synthetic pharmaceuticals.

In developing countries, which represent the majority of the global human population, the use of herbal preparations for medicinal purposes has quite a different but very important significance: in such countries without adequate medical care by hospitals and/or local physicians and/or without an established health care system, traditional (herbal) medicines are usually the only available and affordable treatment [6]. This applies, for example, to some countries or regions in Latin America and Africa where health care is not available to all population groups [6-10].

To the extent that the use of herbal products for therapeutic purposes is substantiated by sound scientific data on quality, safety and efficacy, as required for the authorization of HMP in the European Union, their use is medicinally justified. The appropriate medicinal use is best described in well recognized herbal monographs provided, for example, by the Committee on Herbal Medicinal Products (HMPC) of the European Medicines Agency (EMA; available via www.ema.europe.eu), by the European Scientific Cooperative on Phototherapy (ESCOP; available via www.escop.com) or by the World Health Organization (WHO; available via apps.who.int).

\section{Reasons for Usage of Herbal (Medicinal) Products}

What are the reasons for the great attention herbal products gain? The WHO listed the following main reasons for a preferred use of the entire group of CAM: fear of side effects of synthetic pharmaceuticals, improved access to health information, changing values and lower tolerance against paternalism [2,7]. With regard to developing countries, it is not necessary to evaluate the high importance of all categories of botanical/herbal products and preparations as they are usually the only accessible and affordable treatment options.

In industrialized countries, the interest in HP is mainly based on the assumption of a better tolerability compared to synthetic drugs and sufficient efficacy. This on the one hand due to the long tradition of natural medicine [11] and on the other hand to the frequent belief that HM and HMP are natural and therefore safe compared to synthetic pharmaceuticals [12]. The high recognition is also associated with extensive marketing and advertising of (scientific) information on medicinal properties of the herbal drugs to both lay persons and professionals [5].

Representative surveys in Germany, the market with predominantly authorized HMP, revealed that more than $60 \%$ of the surveyed consumers had concerns about the tolerability of synthetic pharmaceuticals (one of the main reasons identified) and that consumers therefore favor HM and HMP as natural alternatives $[13,14]$.

In the US, data on the use of complementary and alternative medicine (CAM), including herbs and supplements, have been periodically collected since 1997 through the National Health Interview Surveys (NHIS). In 2002, main reasons for using herbs were: trying them out of curiosity (51.5\%) and assuming that herbs combined with conventional therapy would help well than conventional therapy alone (47\%). Other reasons were: assuming that conventional treatment would not help (18.9\%), physician's suggestion to use herbal treatment (15.4\%), and the expensiveness of conventional treatments (14.5\%) [15].

Main reasons for recommending CAM including herbal medicines by general practitioners were the conviction of their therapeutic effectiveness in a patient's respective condition $(68 \%)$, aspects of therapeutic freedom $(47 \%)$ and less harmful side effects than conventional therapies (34\%); monetary reasons (lower price compared with synthetic pharmaceuticals) were also mentioned (6\%) [16].

\section{Epidemiology}

About $50 \%$ of surveyed consumers in Germany reported that they use HMP regularly $[13,14]$.

In the US (17), an estimated 40.6 million adults reported they had used HP supplements in the past 12 months; however, the rate of herb and supplement use dropped slightly from $18.9 \%$ in 2002 to $17.9 \%$ in 2007 and 2012 [18]. Other figures of markets with mainly herbal/botanical supplements like Canada [19] and Australia [20] indicate that roughly $10-20 \%$ of the population use them.

Generally, predictors of CAM including HMP use are gender, age, education, and illness. In industrialized countries like Germany and the US but also in Switzerland, Italy, Denmark, the United Kingdom, Canada and Australia, women, middle-aged people and people with higher education or higher income are more likely to use them than other groups $[5,21,22]$.

\section{Leading Herbals and Leading Indications}

In many regions and countries, the selection of herbal products for medicinal use ultimately depends on marketing and advertising activities, but also on promising and interesting medicinal properties that are proclaimed. Thus, the leading herbal drugs may change over the years.

Leading indications for herbal drugs in Germany were with the indication airway diseases, cough medication, improvement of blood flow, gastrointestinal diseases, diseases of the urinary system, and sedatives including sleep improvement [20]. Similarly, surveys of other opinion polls identified the highest rankings for the common cold as well as stomach and digestive complaints [13]. An epidemiologic study conducted by interviewing more than 20,000 consumers revealed a ranking of airway diseases and cough medication, sleeping disorders, urinary diseases, gastrointestinal diseases, and sedatives [22]. This ranking is reflected by data from surveys in children, which revealed that almost two thirds of herbal medicines are used for the treatment of coughs and colds [23]. In clinical practice, herbal medicinal products are also commonly used for the treatment of joint pain.

In the United States (NHIS data for 2002), the leading indications for herbal drugs were head or chest cold with $29.7 \%$, stomach or intestinal illness with $10.6 \%$, rheumatic diseases with 
$8 \%$, joint pain/stiffness with $6.4 \%$, and anxiety/depression with $5.5 \%$ [15]. In the NHIS of 2012, products containing Echinacea, garlic, cranberry, ginseng, ginkgo biloba, and saw palmetto were most commonly used. All these herbal drugs are taken orally; only comfrey was listed as drug that is used topically [18]. In 2015, herbal supplements made from horehound (Marrubium vulgare) were again the top-selling products of the last years in the mass market (mainstream channel). This was followed by cranberry (Vaccinium macrocarpon) and Echinacea (Echinacea spec.). In the same year, the natural and health food channel was led by turmeric (Curcuma longa) for the third year in a row, followed by grass (wheat or barley; Triticum aestivum or Hordeum vulgare) and flax seed (Linum usitatissimum) [24].

\section{Safety and Responsibility}

As has been stated repeatedly, one of the main reasons for the use of herbal medicines or herbal products is that they are considered natural and therefore, in principle, safer than synthetic medicines [12]. In this context, one should consider the different categories of herbal products on the market, as they affect the safety management: on one side authorized herbal medicinal products with the requirements for quality, efficacy and safety data, on the other side products outside the marketing authorization like remedies.

A medicinal product is authorized on the basis that its riskbenefit ratio for a given indication and target population is positively assessed at the time of authorization. However, many risks associated with the use of a medicinal product will only be discovered and characterized after authorization. This is true also for authorized herbal medicinal products, for which information is continuously increasing post marketing. It is therefore necessary to establish continuous pharmacovigilance activities in order to improve the safety profile of each medicinal product, which is contrary to the actions of countries where the responsibility of the marketed herbal products or botanical supplements without authorization relies solely on the companies' individual responsibility [12]. For this reason, the established methods of pharmacovigilance and risk management for each medicinal product favor the authorization of herbal preparations for medicinal purposes, at least as long as no other sufficient risk management system is established [25].

\section{Conclusion}

Globally, the use of herbal products for medicinal purposes is of great importance. These products are most commonly used in upper airway diseases, including common cold and gastrointestinal disorders. However, herbal medicines also play an important role as sleep medication and in the treatment of joint pain. Authorized or registered herbal medicinal products may best meet a claim by fulfilling high standards of quality, safety and efficacy, as it might be reflected in well recognized herbal monographs.

\section{Conflict of Interest}

None declared.

\section{Aknowledgment}

None.

\section{References}

1. Hung SK, Ernst E (2010) Herbal medicine: an overview of the literature from three decades. J Diet Suppl 7(3): 217-226.

2. WHO, World Health Organization (2013) WHO traditional medicine strategy: 2014-2023. World Health Organization, Geneva.

3. Barnes J, McLachlan AJ, Sherwin CM, Enioutina EY (2016) Herbal medicines: challenges in the modern world. Part 1. Australia and New Zealand. Expert Rev Clin Pharmacol 9(7): 905-915.

4. Enioutina EY, Salis ER, Job KM, Gubarev MI, Krepkova LV, et al. (2017) Herbal Medicines: challenges in the modern world. Part 5. Status and current directions of complementary and alternative herbal medicine worldwide. Expert Rev Clin Pharmacol 10(3): 327338.

5. Sammons HM, Gubarev MI, Krepkova LV, Bortnikova VV, Corrick F, et al. (2016) Herbal medicines: challenges in the modern world. Part 2. European Union and Russia. Expert Rev Clin Pharmacol 9(9): 1117-1127.

6. Bussmann RW, Glenn A, Meyer K, Kuhlman A, Townesmith A (2010) Herbal mixtures in traditional medicine in Northern Peru. J Ethnobiol Ethnomed 6: 10.

7. Abdullahi AA (2011) Trends and challenges of traditional medicine in Africa. Afr J Tradit Complement Altern Med 8(5 Suppl): 115-123.

8. Rodeiro I, Remírez-Figueredo D, García-Mesa M, Dorado P, LLerena A, et al. (2012) Pharmacogenetics in Latin American populations: regulatory aspects, application to herbal medicine, cardiovascular and psychiatric disorders. Drug Metabol Drug Interact 27(1): 5760 .

9. Mosihuzzaman M (2012) Herbal medicine in healthcare - an overview. Nat Prod Commun 7(6): 807-812.

10. Kartal M (2007) Intellectual property protection in the natural product drug discovery, traditional herbal medicine and herbal medicinal products. Phytother Res 21(2): 113-119.

11. Helmstädter A, Staiger C (2012) [Traditional use: phytopharmaceuticals seen from a historical perspective]. Forsch Komplementmed 19(2): 93-98.

12. Wegener T, Deitelhoff B, Silber-Mankowsky A (2015) Drug safety aspects of herbal medicinal products. Wien Med Wochenschr 165(11-12): 243-250.

13. https://www.pharmazeutische-zeitung.de

14. http://www.presseportal.de/pm/52678/2433236.

15. Kennedy J (2005) Herb and supplement use in the US adult population. Clin Ther 27(11): 1847-1858.

16. Thanner M, Nagel E, Loss J (2014) [Complementary and alternative medicine in the German outpatient setting: extent, structure and reasons for provision]. Gesundheitswesen 76(11): 715-721.

17. https://nccih.nih.gov/health/integrative-health

18. Wu CH, Wang CC, Tsai MT, Huang WT, Kennedy J (2014) Trend and pattern of herb and supplement use in the United States: results from the 2002, 2007, and 2012 national health interview surveys. Evid Based Complement Alternat Med 2014: 872320. 
19. Job KM, Kiang TK, Constance JE, Sherwin CM, Enioutina EY. (2016) Herbal medicines: challenges in the modern world. Part 4. Canada and United States. Expert Rev Clin Pharmacol 9(7): 1597-1609.

20. BAH eV (2016) Der Arzneimittelmarkt in Deutschland, Zahlen und Fakten, Bundesverband der Arzneimittel-Hersteller eV. Bonn, Germany.

21. Klein SD, Torchetti L, Frei-Erb M, Wolf U (2015) Usage of Complementary Medicine in Switzerland: Results of the Swiss Health Survey 2012 and Development Since 2007. PLoS One 10(10): e0141985.

22. Raskopf E (2017) Die Versorgungsforschungs-Datenbank PhytoVIs - eine retrospektive Befragung zur Anwendungserfahrung mit Phytopharmaka. GPT Kongress 2017, Muenster, Germany.
23. Du Y, Wolf IK, Zhuang W, Bodemann S, Knöss W, et al. (2014) Use of herbal medicinal products among children and adolescents in Germany. BMC Complement Altern Med 14: 218.

24. Smith T, Kawa K, Eckl V, Johnson J (2016) Sales of Herbal Dietary Supplements in US Increase 7.5\% in 2015. HerbalGram 111: 67-73.

25. Directive 2001/83/EC of the European Parliament and of the Council of 6 November 2001 on the Community code relating to medicinal products for human use (as amended). 